\title{
COMMUNITY AND PUBLIC HEALTH INTERVENTIONS FOR FALL PREVENTION IN BRUNEI
}

\author{
Intervenções comunitárias e de saúde pública \\ para prevenção de quedas em Brunei
}

\author{
Shyh Poh Teo ${ }^{\mathrm{a}}$
}

Brunei has one of the fastest rates of aging in Southeast Asia. In 2000, people aged 60 years and older accounted for $3.9 \%$ of the population, which the United Nations predicts will rise rapidly to $28.7 \%$ by $2050 .{ }^{1}$ Thus, it is important to plan and implement measures to maintain the health and function of older people to reduce dependence and disability. Fall prevention is a priority in an aging population because falls are associated with significant physical and psychological injuries, with associated healthcare-related costs, morbidity and mortality. ${ }^{2} \mathrm{~A}$ public health approach should be considered to attenuate the risk of falls and subsequent negative sequelae in older people. In this paper, community and public health fall prevention initiatives to reduce falls in Brunei are outlined.

The World Health Organization "life course approach" is adopted as the main public health strategy for healthy aging. ${ }^{3}$ This concept views health as an interaction of risk behaviors and protective and environmental factors as cumulative, implying that there is a significant opportunity to prevent illness early in life while the individual is still healthy. In Brunei, there is a high rate of noncommunicable diseases, especially obesity, hypertension, diabetes, ischemic cardiac disease, renal impairment, and dementia. This is likely to contribute to a high rate of disability among older people, which may be prevented prior to presenting to hospital. ${ }^{4}$

In order to apply the 'life course approach', healthy and active information, education and communication (IEC) messages have been drafted for dissemination to the public. Aspects covered include maintenance of an active lifestyle, healthy diet and nutrition, health screening, vaccination, medication management, mental health, fall prevention, and osteoporosis. Once finalized, these IEC messages will form the basis for public health education.

Specific public awareness campaigns on fall prevention have been organized by the Health Promotion Center, Ministry of Health. In 2019, a multidisciplinary road show was held for the public, which required collaboration with clinicians and allied health professionals, such as physical therapists, occupational therapists, and podiatrists. The informative talks and interactive booths during the road show emphasized safe footwear, strength and balance exercises, home safety hazards, and the importance of maintaining good vision.

There is also potential to use mobile technology to disseminate health messages. For example, the mAging program consists of predetermined health messages, including recommendations for fall prevention, which are sent as a text message to recipients. ${ }^{5}$ These messages are intended as reminders of healthy habits, which will hopefully translate into action. The $\mathrm{mAging}$ initiative is currently being piloted at a Senior Citizen Activity Center (Tutong), which will need evaluation regarding the effectiveness of this approach.

aGeriatrics and Palliative Unit, Department of Internal Medicine, Raja Isteri Pengiran Anak Saleha Hospital - Brunei Darussalam.

Corresponding data

Shyh Poh - Geriatrics and Palliative Unit, Department of Internal Medicine, Raja Isteri Pengiran Anak Saleha Hospital - Jalan Putera Al-Muhtadee Billah, Bandar Seri Begawan, BA1710 - Brunei Darussalam. E-mail: shyhpoh.teo@moh.gov.bn

Received on: 03/06/2020. Accepted on: 03/29/2020

DOI: $10.5327 / 22447-212320202000028$ 
A conducive environment is also necessary for fall prevention. The City Car Free Initiative is held every Sunday since 2016 in Brunei, where city centers are blocked off from car traffic. ${ }^{6}$ This enables members of the public to safely engage in physical activity outdoors. The city council encourages events and family activities, including regular tai chi and Zumba sessions. Public buildings and homes should also be fallsafe. The Authority for Building Control and Construction Industry $(\mathrm{ABCi})$ formed a guidelines review committee with input from public and private sectors and stakeholders, including people with disabilities to produce the "Different abilities design guidelines" in $2018 .{ }^{7}$ This takes into account universal design concepts, with an emphasis on accessibility, improved access, and safety. These guidelines are adhered to by the construction industry to ensure that accessible, older person-friendly buildings are built locally.

With respect to specific fall prevention programs, 3 secondary prevention interventions are currently under consideration, namely the Otago Exercise Program, Stepping On, and the Lifestyle-integrated Functional Exercise (LiFE) program..$^{8-10}$ All 3 community-based programs reduce the risk of subsequent falls by approximately one-third. As they have similar rates of fall risk reduction, discussions and focus groups are planned with allied health professionals and older people to identify local preferences for providing and receiving the interventions respectively. The preferred program will have to be adapted and piloted locally to assess feasibility and efficacy in the near future.

Overall, there are several priority actions to develop community and public health responses for fall prevention in Brunei: emphasizing healthy aging using the life course approach, developing and adapting secondary fall prevention interventions, planning an older people-friendly community taking into account environmental risk factors, and strengthening clinical services for the assessment and management of falls.

\section{CONFLICT OF INTERESTS}

The author has no conflict of interests to declare.

\section{REFERENCES}

1. United Nations Department of Economic and Social Affairs. Population Division. World Population Prospects: The 2019 Revision [Internet]. United Nations Department of Economic and Social Affairs, Population Division; 2019 [Accessed in Jan. 14, 2020]. Available from: https:// population.un.org/wpp/

2. Wu S, Keeler E, Rubenstein L, Maglione MA, Shekelle PG. A costeffectiveness analysis of a proposed national falls prevention program. Clin Geriatr Med. 2010;26(4):751-66. https://doi.org/10.1016/j. cger.2010.07.005

3. World Health Organisation. Global strategy and action plan on ageing and health [Internet]. World Health Organisation; 2017 [Accessed in Jan. 14, 2020]. Available from: https://www.who.int/ageing/ WHO-GSAP-2017.pdf?ua=1

4. Teo SP. Geriatrics inpatients in RIPAS Hospital, Brunei: patient characteristics and rehabilitation needs. J Clin Gerontol Geriatr. 2018;9(2):52-8. https://doi.org/10.24816/jcgg.2018.v9i2.04

5. World Health Organisation. Be Healthy Be Mobile: a handbook on how to implement mAgeing [Internet]. World Health Organisation; 2018 [Accessed in Jan. 14, 2020]. Available from: https://www.who.int/ageing/ health-systems/mAgeing/mAgeing-handbook-April2018.PDF?ua=1
6. Kon J. Brunei joins regional neighbours to mark ASEAN Car Free Day. Borneo Bulletin [Internet]. 2018 [Accessed in Jan. 14, 2020]. Available from: https://borneobulletin.com.bn/brunei-joins-regional-neighboursto-mark-asean-car-free-dayl

7. Brunei Darussalam. Ministry of Development. Different Abilities Design Guidelines 2018. Brunei Darussalam: Ministry of Development; 2018

8. Thomas S, Mackintosh S, Halbert J. Does the "Otago exercise programme" reduce mortality and falls in older adults?: a systematic review and meta-analysis. Age Ageing. 2010;39(6):681-7. https://doi. org/10.1093/ageing/afq102

9. Clemson L, Cumming RG, Kendig H, Swann M, Heard R, Taylor K The effectiveness of a community-based program for reducing the incidence of falls in the elderly: a randomized trial. J Am Geriatr Soc. 2004;52(9):1487-94. https://doi.org/10.1111/j.15325415.2004.52411.x

10. Clemson L, Fiatarone Singh MA, Bundy A, Manollaras K, Black D. Integration of balance and strength training into daily life activity to reduce rate of falls in older people (the LiFE study): randomized parallel trial. BMJ. 2012;345:e4547. https://doi.org/10.1136/bmj. e4547 